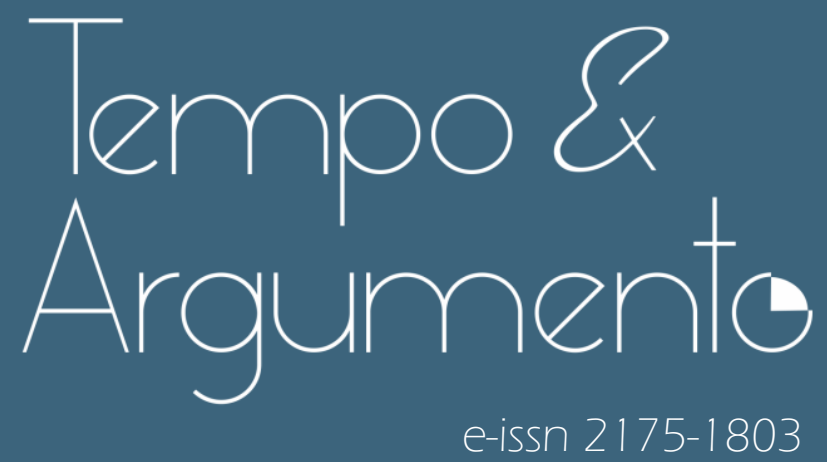

\title{
Debates para (in)disciplinar a história
}

Resenha da obra:

AVILA, Arthur Lima de; NICOLAZZI, Fernando; TURIN, Rodrigo (Orgs.). A História (in)Disciplinada. Vitória: Editora Milfontes, 2019.

- Igor Lemos Moreira

Doutorando em História na Universidade do Estado de Santa Catarina (UDESC).

Florianópolis, SC - BRASIL

lattes.cnpq.br/2889830742673964

igorlemoreira@gmail.com

(D) orcid.org/0000-000 1-6353-7540

Para citar esta resenha:

AVILA, Arthur Lima de; NICOLAZZI, Fernando; TURIN, Rodrigo (Orgs.). A História (in)Disciplinada. Vitória: Editora Milfontes, 2019. Resenha de: MOREIRA, Igor Lemos. Debates para (in)disciplinar a história. Revista Tempo e Argumento,

Florianópolis, v. 12, n. 30, e0602. maio/ago. 2020.

doi http://dx.doi.org/10.5965/2175180312302020e0602

Recebido: 19/05/2020

Aprovado: 25/08/2020 


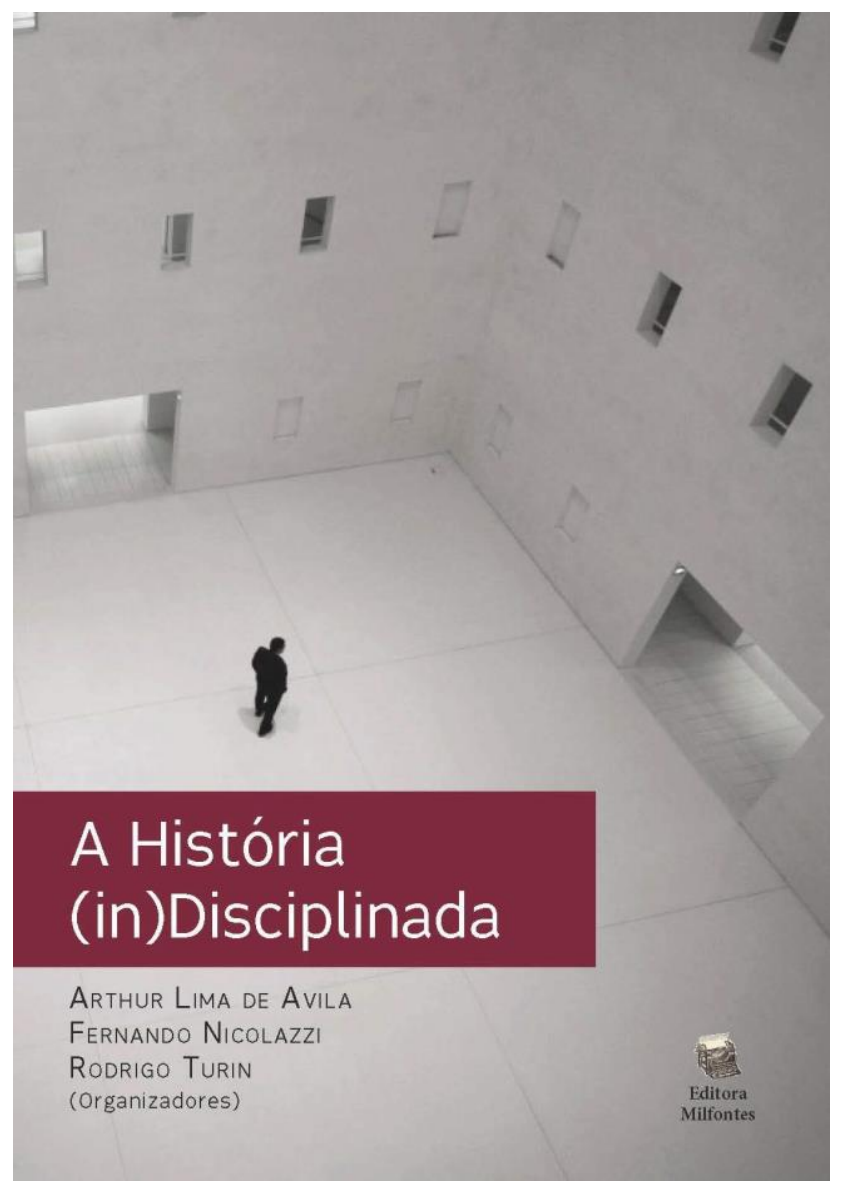

\section{Resenha da obra:}

AVILA, Arthur Lima de; NICOLAZZI, Fernando; TURIN, Rodrigo (Orgs.).

\section{A História (in)Disciplinada.}

Vitória: Editora Milfontes, 2019. ${ }^{1}$

Lançada em 2019 pela Editora Milfontes, a coletânea $A$ história (in)disciplinada é resultado de três encontros realizados pelo Laboratório de Estudos sobre os Usos Políticos do Passado (Luppa), da Universidade Federal do Rio Grande do Sul, entre 2016 e 2018. Organizado pelos historiadores Arthur Lima de Avila, Fernando Nicolazzi e Rodrigo

Turin, o livro aborda problemas de caráter epistemológico relevantes para a construção da disciplina. Os questionamentos centrais da obra são os seguintes: 1) Quem elabora as "regras e categorias" que constroem a disciplina, e como são elaboradas? 2) É possível "indisciplinar" uma disciplina, ou seja, repensar seu lugar social e as demandas existentes como parte de sua própria epistemologia? 3) O que pode ser definido como indisciplinar em relação à História? 4) São maleáveis, como discursivamente o afirmam, as relações que constituem e definem o campo dos/as historiadores/as, dimensionando suas regras e categorias, ou existe uma "estrutura" rígida que impossibilita repensar a disciplina?

Entendemos que as possíveis respostas para esses questionamentos são importantes para o estudo da História do Tempo Presente. Para os organizadores, “a indisciplinarização da disciplina [...] diz respeito, antes, a uma dimensão ativa, no sentido de tomar posição e de ser ator nesse processo de profundas

\footnotetext{
'Resenha produzida com apoio da Coordenação de Aperfeiçoamento de Pessoal de Nível Superior - Brasil (Capes) - Código de Financiamento 001.
} 
transformações na relação entre passado, conhecimento, ensino e sociedade" (AVILA; NICOLAZZI; TURIN, 2019, p. 13). Ao propor (re)pensar a disciplina aos/ás autores/s que integram o livro, os organizadores destacam a constituição da História como campo mediado pelos próprios historiadores/as, sendo eles/as responsáveis por suas configurações e bases. O livro é composto por oito capítulos, nos quais se apresentam discussões sobre as regras e definições do campo, as práticas dos/as historiadores/as que configuram a disciplina e a formulação de categorias e reflexões no tempo presente.

O capítulo “O que significa indisciplinar a história?”, escrito por Arthur Lima de Avila, que abre a coletânea, discute as bases da historiografia disciplinar. 0 historiador defende a desnaturalização de princípios disciplinares da História, tais como a universalidade ou a necessidade de recuo temporal com relação às urgências do tempo vivido. Para o autor, essas operações não levariam à descaracterização da disciplina, mas a um "abrir-se" a demandas emergentes. Avila destaca que a disciplina História vive, desde o final do século XX, sob "constantes crises", em função da incapacidade da área de "olhar para si" a partir de demandas colocadas pelo tempo presente. Neste sentido, o autor enfatiza a urgência de os/as historiadores/as compreenderem a diferença entre "profissão" e "disciplina".

No capítulo "A história disciplinada e seus outros: reflexões sobre as (in)utilidades de uma categoria”, a historiadora Maria da Glória de Oliveira aborda a necessidade de discutir as normas que regem a disciplina a partir da categoria "gênero". Tendo em vista um levantamento publicado na revista História da Historiografia, a historiadora constatou a pouca presença, no periódico, de historiadoras escrevendo sobre a teoria da história e da história da historiografia. Para a autora, algumas áreas da disciplina - tal como a da teoria da história e da historiografia - ainda se caracterizavam por uma maior produção de pesquisas realizadas por homens.

Lidiane Soares Rodrigues, no capítulo " $A$ doxa da heterodoxia: a avaliação dos pares e as condições de transgressão disciplinar", problematiza a contradição entre o discurso sobre a necessidade de interdisciplinaridade na historiografia e as práticas de avaliação de artigos em periódicos científicos. A autora, que teve 
sua formação em História e o estágio pós-doutoral na área da Sociologia, redigiu o capítulo a partir de sua própria experiência. A historiadora teve um artigo rejeitado por pareceristas da revista História da Historiografia, a partir de divergência sobre o que era "aceitável" como interdisciplinaridade. O texto apresentava uma reflexão sobre as relações vigentes entre História e Sociologia a partir dos ensinamentos do pensador francês Pierre Bourdieu. A reflexão de Rodrigues aponta para o desafio metodológico da operacionalização de categorias e conceitos pertencentes ao campo ampliado das humanidades nos "diálogos" entre a História e outras áreas das ciências humanas.

O capítulo "Qualis periódicos na área de história: alguns apontamentos sobre os pressupostos, os resultados e os possíveis efeitos de uma avaliação", de Rafael Faraco Benthien, problematiza a influência dos processos de avaliação das revistas acadêmicas na área de História como instrumentos de hierarquização e constituição do campo. A partir da análise de dados da Coordenação de Aperfeiçoamento de Pessoal de Nível Superior (Capes), o autor destaca que a pesquisa na área de História no país ainda está concentrada nos meios universitários, que se destacam como centros intelectuais que determinam ou impõem as regras do campo historiográfico. O autor debate as tensões nas atribuições de Qualis em revistas, atentando para o fato de que este é elaborado por integrantes do campo, guiados por referências e critérios gerais estabelecidos pela Capes para todas as revistas científicas. Tal processo leva à criação de parâmetros que desconsideram especificidades das ciências humanas, pois são criadas para avaliar todas as revistas científicas, desde as ciências exatas e da natureza até as humanas, independentemente de sua área de conhecimento.

O campo universitário também é analisado por Mara Cristina de Matos Rodrigues, tendo como foco o ensino de Teoria da História no âmbito da graduação. No capítulo "Ensino de teorias e metodologias nos cursos de graduação em história: sobre silêncio, poder e presença”, a autora utiliza sua experiência como docente, em diálogo com análises inovadoras no campo do ensino de história, para questionar: "Que teoria da história é essa que ensinamos e que serve de base para nossas pesquisas?” (MATOS RODRIGUES, 2019. p. 151). 
Partindo da crítica às perspectivas ortodoxas, que relegavam questões de gênero, classe social, sexualidade e raça a segundo plano (ou mesmo as ignoravam), propõe repensar o ensino universitário da disciplina a partir das demandas do presente e, mais particularmente, das especificidades do caso brasileiro. Para a autora, esse processo poderá ocorrer por meio da introdução de novas linguagens, assim como pela construção de saberes não centrados apenas na Europa e/ou produzidos por homens.

O capítulo "Narrativas populares no Museu Universal: a experiência do tempo para além da história disciplinar", de autoria do historiador Valdei Araujo, debate sobre a escrita da História no Brasil do século XIX. A partir do impresso "Museu Universal", o autor realiza uma análise das narrativas "populares" que circularam através da publicação. Araujo destaca o fenômeno global das “narrativas populares", produzidas por pessoas que não tinham formação acadêmica, inferindo sobre a importância desses homens e mulheres na construção de "imagens" sobre as nações. O autor enfatiza, no texto, a importância desses processos de produção de discursos sobre a história e suas relações com o desenvolvimento de tecnologias de construção historiográfica no tempo, ou seja, sobre a importância das questões presentes nas discussões contemporâneas sobre História Pública e os usos do passado.

Intitulado "Culturas de passado e eurocentrismo: o périplo de tláloc", o capítulo de autoria de Fernando Nicolazzi se inicia com a discussão do manifesto \#THEORYREVOLT², publicado em maio de 2018, com o objetivo de situar os/as leitores/as sobre embates no campo da teoria da História. A partir dessa contextualização, o autor aborda a necessidade de se debaterem as concepções de tempo histórico e de eurocentrismo (NICOLAZZI, 2019. p. 220), propondo a

\footnotetext{
Publicado em maio de 2018, o manifesto THEORYREVOLT foi assinado pelo coletivo Wild On, composto por Joan Scott, Ethan Kleinberg e Gary Wilder, que nele defendem a existência, na historiografia contemporânea,de um movimento de sobreposição da empiria sobre a teoria. Ou seja, que o foco da disciplina em arquivos e na experiência das pessoas havia relegado a teoria da história a segundo plano. Segundo Nizolazzi (2019, p. 212), essa publicação aponta três motivos principais para o descompasso entre a teoria e a empiria diagnosticado pelo coletivo nessa publicação: "os limites da história disciplinar, a (suposta?) resistência de historiares de historiadoras à teoria, e a relação nem sempre considerada com a devida seriedade entre aporte teórico e dimensão crítica na historiografia.". Uma versão traduzida do manifestado pode ser consultada em: KLEINBERG, Ethan; SCHOTT, Joan; WILDER, Gary. Teses sobre Teoria e História. Wild On. 2018. Disponível em: https://bit.ly/2P7hpnX. Acesso em: 19 ago. 2020
} 
utilização da categoria de "culturas de passado" como ferramenta para a compreensão das diferentes formas como os indivíduos e os grupos sociais se relacionam com o passado, percebendo suas significações no e para o presente. Para demonstrar esse processo, Nicolazzi analisa o périplo de tláloc, monumento esculpido em basalto, que representa a divindade das chuvas abundantes e da agricultura, encontrado no povoado San Miguel de Coatlinchán (México). O autor descreveu seus significados para as comunidades locais, bem como os processos de reapropriação e resignificação por representantes do governo mexicano no ato da transferência da "pedra", que passou a ser considerada monumento, razão que justificou sua incorporação no Museu Nacional de Antropologia.

O último capítulo da obra, de autoria de Rodrigo Turin, intitula-se "Presentismo, neoliberalismo e os fins da história". Por meio de um exercício de análise sobre o considerado presente, o historiador aponta para as mudanças de sentido em conceitos e paradigmas do pensamento social brasileiro a partir da emergência do neoliberalismo desde o final do século XX. O autor apresenta reflexões no sentido de que a racionalidade neoliberal (tempo das finanças) passou a nortear uma perspectiva temporal que, paulatinamente, está se tornado global. Turin questiona, ainda, se o "mundo ocidental" está imerso em uma nova experiência temporal ou, então, se deveríamos compreender que o tempo vivido é marcado por uma crise de paradigmas caracterizada pelo caos.

As reflexões propostas na coletânea inserem-se em discussões realizadas no Brasil nos últimos anos, em função de uma série de embates sociais e políticos em torno da própria disciplina, tais como a criação das Base Nacionais Curriculares, ou a "reforma" realizada no currículo nacional do ensino médio. Esse contexto é marcado pelos usos públicos do passado, pelos usos comerciais da história e pelas tentativas de revisionismo que negam ou relativizam eventos traumáticos da história brasileira e mundial, como o Holocausto, a ditadura civilmilitar e a escravidão. As provocações a respeito da necessidade de repensar a História e a Historiografia a partir de outros olhares, incorporando não apenas novos debates, mas sujeitos e demandas da contemporaneidade presentes nos 
capítulos, evocam discussões ocorridas nacionalmente em torno do campo da História Pública e da História do Tempo Presente.

Em linhas gerais, a obra A História (in)disciplinada é um livro provocante que levanta reflexões urgentes e fundamentais para a historiografia contemporânea. A publicação da coletânea ocorre em um período de retomada das discussões do lugar social da História e dos/as historiadores/as no país, levantando a importância de se refletir a respeito de suas configurações e de seu papel na interpretação das realidades brasileiras. A obra, neste sentido, apresenta um perfil bastante crítico e estimulador para as reflexões da História do Tempo Presente, pois aponta os desafios, as limitações e potencialidades da chamada prática de indisciplinar a história na configuração de outras interpretações sobre passados, presentes e futuros. De certa forma, algumas questões sobre a (in)disciplinarização retomam discussões anteriores, a exemplo dos escritos de Susan Sontag (2020).

Apesar de não constar nas referências da publicação, é possível estabelecer diálogos da coletânea com os escritos de Sontag (2020) a respeito de questões que envolvem a "interpretação" do mundo como processo que cria instrumentos rígidos de análise e produção, sendo necessário repensar constantemente essa prática, a fim de atender às demandas do tempo vivido. Neste sentido, indisciplinar a história é não apenas um posicionamento teórico, mas um desafio metodológico de se colocar em diálogo, com atenção para o presente, entendendo o papel central por ele ocupado na área de História.

Cabe destacar que a obra não é uma produção definitiva sobre as pesquisas apresentadas. A coletânea resulta de debates em andamento no campo da teoria da História e da Historiografia, sendo o registro de reflexões em andamento e um convite a historiadores/as para deles participarem. Mais do que proposição de respostas, a obra é um registro e um ponto de partida para os debates atuais sobre a Teoria da História e a disciplina no tempo presente. Essas demandas contemporâneas por novos posicionamentos, de inserção pública dos historiadores e de regulamentação da profissão, levantam alguns questionamento: Como ficam os/as historiadores/as que seriam, em parte, as vozes "autorizadas" a se pronunciar sobre o passado? Como pensar a disciplina 
frente às crises instaladas por um desejo sobre informações de "passados", mas não necessariamente de História?

A coletânea A História (in)Disciplinada apresenta-se, neste sentido, como uma obra importante para o debate, ao lembrar a necessidade de se repensar seu lugar social e a urgência de se tomar e rever posições. Como destacam os organizadores, talvez a Indisciplinarização da História seja uma forma de politizar o saber e de se recarregar o potencial de nosso campo disciplinar frente aos mencionados cenários.

\section{Referências}

AVILA, Arthur Lima de; NICOLAZZI, Fernando; TURIN, Rodrigo (Orgs.). A História (in)Disciplinada. Vitória: Editora Milfontes, 2019.

SONTAG, Susan. Contra a interpretação e outros ensaios. São Paulo: Companhia das Letras, 2020.de

KLEINBERG, Ethan; SCHOTT, Joan; WILDER, Gary. Teses sobre Teoria e História. Wild On. 2018. Disponível em: https://bit.ly/2P7hpnX. Acesso em: 19 ago. 2020. 